\title{
Questões de linguagem médica
}

\section{Issues of medical language}

\author{
Simônides Bacelar ${ }^{1}$; Elaine Alves ${ }^{2}$; Wânia de Aragão-Costa3; ${ }^{3}$ Paulo Tubino ${ }^{4}$
}

A linguagem é livre. Essencial é a comunicação. Quando se sabe disso, os conceitos de "certo" e "errado" são substituídos pelos conceitos de escolhas verbais - entre todas as formas existentes da língua, em suas variedades de linguagem popular e culta - "adequadas" e "não-adequadas". Mesmo os termos mais chulos calham em situações emotivas extremas.

Para exercício desta liberdade de linguagem, precisa-se de conhecer o patrimônio do idioma. É mister saber que as transformações pelas quais uma língua passa determinam-se pelos seus usuários, seus verdadeiros autores, pelas necessidades culturais e históricas de uso. Mais ainda, que o atingimento das metas de comunicação daquela situação específica - a efetividade do que se vai falar ou escrever - tem de guiar nossas decisões gramaticais.

Quando se trata de linguagem científica, por sua seriedade e sua rigorosidade, convém ter domínio do padrão gramatical culto, normativo, descrito e organizado, ao longo de séculos, pelos profissionais de Letras. A linguagem científica formal tem características próprias, apregoadas - em todos os tempos - por bons orientadores médicos, exemplificados nos excertos que se seguem:

Se a precisão da linguagem é necessária a todos, ela é imprescindível aos pesquisadores e cientistas, já que a imprecisão é incompatível com a ciência '.

A idade de um erro não lhe confere exatidão, e desconhecer e teimar em usar termos impróprios não é sinal de independência e nacionalidade, mas de pura ignorância afirmou Hélio Wernech ${ }^{2}$.

Palavras homógrafas com significados diferentes devem ser evitadas na linguagem científica. O ideal é que cada coisa seja designada por um só termo e que cada termo designe uma só coisa ${ }^{3}$.

Creio que já é tempo de os professores das nossas faculdades de medicina interessarem-se pela terminologia. Sou mesmo de parecer que, nos concursos, mesmo os de livre docência, dever-se-ia fazer questão cerrada da uniformidade e do rigor terminológico. De fato, é claro que quem se propõe a ensinar deve saber rigorosamente o que vai ensinar e, se não the conhecer o nome aos elementos das ciências que se propõe a lecionar, como poderá fazê-lo cabalmente? ${ }^{4}$

Na linguagem científica, o ideal é nunca usar duas palavras para exprimir a mesma coisa, nem dar o mesmo nome a duas coisas diferentes (Sir Thomas Clifford Albert, 1836-1925, médico inglês).

Tendo em vista o que se leu e outras tantas considerações de igual teor, comentam-se os a seguir alguns termos que, embora muito freqüentes na linguagem médica, ensejam controvérsias quanto a seu uso em padrão formal, mesmo no âmbito médico. Pode ser opção mais vantajosa, mais efetiva, escolher usos sobre os quais não pesem questionamentos ou sobre os quais haja menor possibilidade de questionamentos, o que é possível em quase todos os casos.

Cirurgia - Operação. Do grego kheir, mão, e érgon, trabalho, "cirurgia" é nome que expressa, literalmente, trabalho manual. Como o cirurgião trabalha com as mãos e com elas manipula instrumentos cirúrgicos para operar, a etimologia respalda o uso, comum entre médicos, de cirurgia em lugar de operação. Com efeito, cirurgia é registrada como sinônimo de operação em alguns dicionários ${ }^{5,6}$. Observa-se mesmo que o nome "cirurgia" pode ser útil para afastar ambigüidades, como na expressão "operações para incontinência urinária", que sugere outros tipos de procedimento adotados para esta anomalia, incluindo-se os cirúrgicos. Como reforço a esse uso, está consagrada a nominação "videocirurgia" em vez de "videooperação". Contudo, os léxicos definem "cirurgia" essencialmente como ramo da Medicina que se dedica ao tratamento de doenças, lesões ou deformidades por meio de operações, intervenções ou procedimentos cirúrgicos. Com este valor, "cirurgia" é averbada nos dicionários Aulete $^{7}$, Aurélio $^{8}$, Silveira Bueno ${ }^{9}$, Michaelis ${ }^{10}$ e nos dicionários de termos médicos de Cardenal ${ }^{11}$, Fortes \& Pacheco ${ }^{12}$, Paciornik ${ }^{13}$, Pedro Pinto ${ }^{14}$ e muitos outros. Daí, por essa referência lexical, "cirurgia" tem - como significado principal - especialidade ou disciplina: Cirurgia Cardiovascular, Cirurgia Pediátrica, Cirurgia Geral.

Assim, levanta-se o questionamento sobre o uso preferencial, no âmbito médico, do termo "cirurgia" para designar o ato operatório, já que este uso pode causar dissentimentos entre leitores e ouvintes exigentes que usam "operação" em lugar de "cirurgia" para designar o ato cirúrgico. Por conformidade com o significado principal do termo em questão, pode-se também usar ato cirúrgico, procedimento cirúrgico, intervenção cirúrgica em lugar de "cirurgia". Pode-se dizer: operação de Duhamel, operação

Trabalho realizado no Hospital Universitário de Brasília, DF, BR.

1. Médico; Professor Voluntário do Hospital Universitário de Brasília, UnB, DF, BR; 2. Professora Associada do Hospital Universitário de Brasília, UnB, DF, BR; 3. Professora Adjunta da Língua Portuguesa da Universidade de Brasília, DF, BR; 4 . Professor Emérito do Hospital Universitário de Brasília, UnB, DF, BR. 
de Heller, operação de Wertheim. Pode-se também empregar "tratamento cirúrgico" ou "correção cirúrgica". Observe-se que se diz "reoperação" e, não, "recirurgia"; em geral, mencionam-se períodos pré-operatório, intra-operatório, peroperatório, transoperatório e pós-operatório em vez de pré-cirúrgico, intracirúrgico, percirúrgico ou pós-cirúrgico. Para constar, há outras opções: técnica de Alcino Lázaro, técnica de Stoppa, técnica de Shouldice; ou nomes específicos: cardioplastia à Thal, cardiomiotomia à Heller, piloromiotomia extramucosa, gastrectomia subtotal.

Há casos menos usados. O termo "intervento", como substituto de "cirurgia", é neologismo, até o momento ausente dos dicionários. Com este significado, está registrado "interventivo", nome tomado ao latim interventus, particípio passado de intervenire, equivalente a "intervindo" em português, mas não é usado em medicina como sinônimo de "cirurgia" ou de "operação". A expressão "paciente cirurgiado", também neologismo, aparece nos anais do XVI Congresso de Cirurgia Pediátrica.

É oportuno lembrar que é questionável citar o nome da doença como nome da operação: "Paciente fez uma hérnia." . "O cirurgião está fazendo uma apendicite.". "Foi internado para uma fimose.". Por associação, quando não for referência a "cirurgia", pode-se usar "operatório": "tratamento operatório", em lugar de "tratamento cirúrgico", por exemplo.

Em resumo, a consagração de "cirurgia" na linguagem médica para designar um ato cirúrgico torna legítimo este termo. Entretanto, por seu amplo uso, "operação" é nome consagrado na linguagem geral e, se for mais utilizado no meio médico, pode salvaguardar o nome "cirurgia", este como um termo de sentido mais elevado quando abrange um ramo da Medicina, uma disciplina ou uma especialidade profissional.

Patologia. Embora sejam comuns na linguagem médica, têm sido objeto de antagonismos, no âmbito médico expressões, como "patologia rara", "patologia congênita", "patologia severa", "patologia de base", em que se usa "patologia" como sinônimo de "doença". Há desconchavo semântico nessas expressões. Nos dicionários em geral, com inclusão dos especializados, "patologia" não é averbada como sinônimo de "doença". No Dicionário Houaiss ${ }^{15}$ consta "patologia", não adequadamente, como "desvio anatômico e/ou fisiológico que se constitua doença". No entanto, o Dicionário Garnier \& Delamare ${ }^{16}$ dá esta notificação no verbete "patologia": "Este termo é freqüentemente empregado incorretamente no sentido de doença ou mesmo (anglicismo) de anatomopatologia" 16.

Em rigor, patologia é a ciência que trata das doenças, não a própria doença. Também é uma disciplina. É o estudo das doenças, isto é, dos distúrbios anatomofisiológicos que caracterizam doença, não a doença em si. Provém do grego pathé, doença, sofrimento, e lógos, tratado, estudo, discurso, fala, raciocínio, o que se diz da doença. Desse modo, inclusive, a expressão "o estudo da patologia" é pleonástica. Diz-se mais adequadamente: doença de base ou doença rara, doença pulmonar.
Há outras questões que demandam reflexão: em "Tumores de língua são uma patologia freqüente.", por exemplo, há certa impropriedade, já que todas as variedades de tumores de língua afiguram-se como uma só "patologia". Pode-se dizer: "Tumores de língua são afecções freqüentes." . Usa-se, também, "patologia" como sinônimo de "sinal" ou de "sintoma": "A diarréia é uma patologia comum na infância.". Mais cuidadosamente, diz-se: "patologia cirúrgica" em referência ao estudo das doenças que necessitam de operações; "patologia cirúrgica" da criança refere-se ao estudo ou ao tratado das doenças cirúrgicas da criança; "patologia pulmonar" significa tratado ou estudo das doenças do pulmão. Por análise comparativa, não se diz, por exemplo, que um paciente teve uma pneumologia ou que apresentou uma dermatologia, e, sim, uma pneumopatia ou uma dermopatia ${ }^{17}$. Note-se, também, que usualmente não se mencionam: patologia de Gaucher, patologia de Hirschsprung, patologia de Crohn.

"Patologia" como "doença" pode significar acoIher mais um caso de dubiedade, figura apontada como imperfeição de linguagem por qualificados conhecedores de línguas. "Patologia" não tem, desse modo, fundamentos etimológicos ou semânticos para significar "doença" na linguagem culta, apesar de seu amplo uso neste sentido. Ao lado disso, é importante verificar que a sinonímia de "doença" é muito vasta, o que poderia dispensar a necessidade de incluir, nela, "patologia". Pode-se lançar mão de nomes genéricos, como: acometimento, adoecimento, afecção, agravo, anomalia, anormalidade, caso, comprometimento, condição, defeito, defeito congênito, deformidade, desarranjo, desconforto, doença, desordem, desordem congênita, defeito, defeito congênito, disfunção, diagnóstico, distúrbio, endemia, enfermidade, entidade clínica ou cirúrgica, entidade mórbida, epidemia, estado, estado mórbido, evento, evento mórbido, fenômeno mórbido, indisposição, lesão, mal-estar, mal, moléstia, malformação, má-formação, maladia, morbidade, morbo, morbose, padecimento, perturbação, processo, sofrimento, transtorno, caso cirúrgico, caso clínico; ou específicos: associação, combinação, seqüência, enteropatia, hepatopatia, pneumopatia, dermatose, toxicose, nefrose, artrose, micose, hepatite, cardite, encefalite, síndrome, díade, tríade, tétrade, além dos nomes da própria doença. Por haver tantas expressões mais adequadas, acatados gramáticos e estudiosos de linguagem não indicam "patologia" como sinônimo de "doença".

A procura de um nome técnico para expressar doenças em geral pode explicar, entre os médicos, o uso do termo "patologia", a configurar o que os gramáticos chamam de catacrese, como ocorre com "pé" ou "braço" de cadeira. Há procuras mais expressivas. Nos Anais do XVIII Congresso Brasileiro de Psiquiatria (2000), página 31, por exemplo, consta: "Da patologia do sintoma ao pathos sintomático do sujeito". Ideal seria usar o termo patia, que infelizmente inexiste no léxico, mas pode-se aditá-lo como sufixo: artropatia, hepatopatia, neuropatia. 
Quando uma palavra é usada por todos, mesmo inadequadamente, com o tempo, poderá ser considerada como legítima, mas somente será incluída na linguagem culta após o questionamento e o estudo dos especialistas em Letras que a legitimem. Numerosos termos difusamente disseminados na linguagem médica ainda não são oficialmente codificados, como interar, interter, esterelizar, umbelical e outras formas da linguagem de cunho mais popular. Há, em adição, numerosos termos com a terminação -logia, além de "patologia", usados fora do significado científico preciso. É recomendável, portanto - a fim de que se possa falar e escrever, principalmente no exercício profissional, com clareza, precisão e efetividade - prestar cuidados para que termos científicos não sejam oficializados com formas ou sentidos inadequados por influência da soberania da "lei do uso", assim como é de boa norma sempre promover esforços para que a linguagem médica tenha também um certo "padrão-ouro", como os estabelecidos em outros aspectos da Medicina.

\section{A B S T R A C T}

The language is free and, for it's manifestation, it's necessary to know the whole idiom. It's imperious to know trat all the changes of a specific language, are due to their users, their real authors. The scientific language, because of it's extreme rigidity, should have an accurate grammar construction, with a clear organization. In this paper, we describe some terms, posted in medical articles, that are controversial, even in this medical environment.

\section{REFERENCIAS}

1. Goldenberg S. Publicação do trabalho científico: compromisso ético. São Paulo; 2007 [citado em 2008 Dec 16]. Disponível em: http:/ /www.metodologia.org/saul_etica

2. Wernech H. Nomina anatômica. $5^{a}$ ed. Rio de Janeiro: Medsi; 1984. p. 39-40.

3. Rezende JM. Linguagem médica. Goiânia: AB 2004. 472 p

4. Mangabeira-Albernaz P. Questões de linguagem médica. Rio de Janeiro: Atheneu; 1944. p. 9-20.

5. Luft CP. Minidicionário Luft. 3ª ed. São Paulo: Ática; 1991.

6. Rey L. Dicionário de termos técnicos de medicina e saúde. $2^{\text {a }}$ ed. Rio de Janeiro: Guanabara Koogan; 2003.

7. Aulete C, Garcia H, Nascentes A. Dicionário contemporâneo da língua portuguesa. 3a ed. Rio de Janeiro: Delta; 1980.

8. Ferreira $A B H$, Ferreira MB, Anjos M. Novo dicionário Aurélio da língua portuguesa, 3. ${ }^{a}$ ed. Curitiba: Positivo; 2004.

9. Bueno FS. Dicionário da língua portuguesa. São Paulo: Lisa; s.d.

10. Michaelis. Moderno dicionário da língua portuguesa. São Paulo: Melhoramentos; 1998.

11. Cardenal L. Diccionário terminológico de ciências médicas. $6^{a}$ ed. Barcelona: Salvat; 1958.

12. Fortes H, Pacheco, G. Dicionário médico. Rio de Janeiro: Editor Fábio Mello; 1968.
13. Paciornik R. Dicionário médico. 2a ed. Rio de Janeiro: Guanabara Koogan; 1975.

14. Pinto PA. Dicionário de termos médicos. $8^{a}$ ed. Rio de Janeiro: Científica; 1962.

15. Houaiss A, Salles VM, Franco FMM. Dicionário Houaiss da língua portuguesa. $1^{\text {a }}$ ed. Rio de Janeiro: Objetiva; 2001.

16. Garnier M, Delamare J, Delamare V, Delamare T. Dicionário Andrei

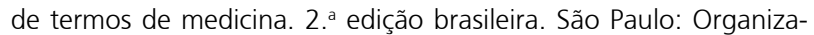
ção Andrei Editora; 2002.

17. Rezende JM. Linguagem médica. São Paulo: Fundo Editorial Byk; 1992.

Recebido em 01/10/2008

Aceito para publicação em 26/11/2008

Conflito de interesse: nenhum

Fonte de financiamento: nenhuma

Como citar este artigo:

Bacelar S, Alves E, Aragão-Costa W, Tubino P. Questões de linguagem médica [comunicação científica]. Rev Col Bras Cir. [periódico na Internet] 2009; 36(1). Disponível em URL: http://www.scielo.br/rcbc

\section{Endereço para correspondência:}

Simônides Bacelar

E-mail: simonides@uol.com.br 